\title{
Integridad, competencia restringida y COVID-19: retos para la contratación pública peruana
}

\author{
Mg. Christian Chocano Davis* \\ Pontificia Universidad Católica del Perú \\ christian.chocano@gmail.com \\ Código ORCID: https://orcid.org/0000-0002-7313-5745
}

\section{Resumen:}

La pandemia de la COVID-19 ha evidenciado algunos retos para la integridad y eficiencia en la contratación pública peruana. Este artículo analiza los procedimientos que las entidades públicas han usado para contratar los bienes y servicios necesarios para atender la emergencia sanitaria: la contratación directa por situación de emergencia, las contrataciones menores o iguales a ocho unidades impositivas tributarias, la comparación de precios, los catálogos electrónicos de acuerdos marco, el contrato por encargo y la contratación internacional. Este análisis incluye oportunidades de mejora para un mejor uso de la contratación pública.

Palabras clave: integridad; contratación pública; COVID-19; contratación directa; competencia restringida

\begin{abstract}
:
"Integrity, restricted competition and COVID-19: challenges for Peruvian public procurement". The COVID-19 pandemic has shown some integrity and efficiency challenges in Peruvian public procurement. This article analyses procedures used by public entities to purchase the necessary goods and services for responding to the sanitary emergency: direct awards due to emergency situations, procurements whose amounts are equal or less than eight penalty tax units, price comparison studies, framework agreements, commissioned purchases and international contracts. This analysis includes areas of improvements for a better use of public procurement.
\end{abstract}

Keywords: integrity; public procurement; COVID-19; direct awards; limited tendering

Recibido: 14.10 .2020

Aceptado: 06.12.2020

\footnotetext{
* Abogado por la Pontificia Universidad Católica del Perú y Máster en Derecho por la Universidad Católica de Lovaina. Docente del curso Empresa y Contratación con el Estado de la maestría de Derecho de la Empresa de la PUCP y del curso Ética y Responsabilidad Profesional del Abogado de la Facultad de Derecho de la misma casa de estudios. Supervisor de mejora de procesos y estandarización de la Dirección Técnico Normativa del Organismo Supervisor de las Contrataciones del Estado. Ha realizado diversas publicaciones y capacitaciones sobre temas de contrataciones del Estado, obras públicas, arbitraje e integridad. Este artículo no refleja una opinión institucional (christian.chocano@gmail.com)
} 


\section{Introducción}

La situación de emergencia generada por la propagación de la COVID-19 es una prueba a la vocación de servicio. Miles de servidores públicos alrededor del mundo han perdido sus vidas en la primera fila de batalla. Es enorme la magnitud de los daños que esta crisis global genera en la salud, el empleo y la calidad de vida de las personas. Incluso se ha planteado que el coronavirus tendrá un impacto en la democracia y la gobernanza, debido al riesgo de consolidación del autoritarismo (Brown, Brechenmacher \& Carothers, 2020).

En tiempos de pandemia, es de esperar que los funcionarios actúen motivados por la vocación de servicio con la mayor eficiencia y empeño, dejando de lado cualquier aprovechamiento personal en el uso de los recursos públicos.

Los servidores públicos debieran actuar motivados por un elevado estándar de integridad pública, que es definida por la Organización para la Cooperación y el Desarrollo Económicos (OCDE) como la "alineación consistente y la adhesión a valores, principios y normas éticos compartidos para mantener y priorizar el interés público sobre los intereses privados en el sector público" (OCDE, 2017).

La esencia de la integridad en el sector público radica en esa prevalencia del interés público por sobre el interés privado. La integridad exige que quien ejerce función pública esté en condiciones de identificar un conflicto de intereses y hacer prevalecer el interés público por sobre cualquier interés personal. Este es el núcleo duro que todo profesional que ejerce función pública debe interiorizar, valorar y ser consecuente en cada acción.

Lamentablemente, durante tragedias y circunstancias excepcionales es usual que haya quienes busquen aprovechar la oportunidad de usar de manera indebida los recursos públicos. Gallego, Prem y Vargas han realizado un análisis estadístico y concluido que, después del arribo de la pandemia a Colombia, se evidenció un incremento diferencial en el uso y valor de las potestades discrecionales en la contratación pública por parte de las municipalidades que, según la línea de base, tenían mayor probabilidad de corrupción (Gallego, Prem y Vargas, 2020).

En el Perú, los medios de comunicación han informado reiteradamente de diversas irregularidades en contrataciones de bienes y servicios vinculados a la emergencia sanitaria ocasionada por la propagación de la COVID-19, tales como la compra de bienes a precios sobrevalorados o a empresas sin trayectoria de comercialización y que no cumplían con las habilitaciones legales correspondientes. Asimismo, la Contraloría General de la República ha identificado que más de doce mil funcionarios habrían recibido canastas básicas familiares, pese a no calificar como población vulnerable ${ }^{1}$.

En última instancia, esta realidad no es extraña si se considera que el Perú se ubica en el puesto 101 de 198 países en el índice de percepción de corrupción de Transparencia Internacional, con una puntuación de 36 sobre 100 puntos, por debajo de la media (2019). Del mismo modo, el pilar de control de corrupción en Perú de los indicadores de gobernanza del Banco Mundial no muestra mejoría alguna en los últimos años (Kaufmann y Kraay, 2018).

Ahora bien, la contratación pública como sistema debe ser capaz de premiar a quienes ejercen la función pública con vocación de servicio y castigar a quienes buscan una oportunidad para cometer prácticas corruptas. Además, debe ser capaz de prevenir 
que ocurran prácticas contrarias a la integridad, ya que un énfasis desmedido en el control antes que en la prevención afecta la capacidad de procesamiento de denuncias y enjuiciamiento de responsables.

En un trabajo previo he evaluado las herramientas que la normativa de contratación pública contiene para promover integridad y he propuesto algunas oportunidades de mejora concretas. Asimismo, he mencionado que para hacer frente al problema de la corrupción en este ámbito de actividad del Estado se requiere de una estrategia integral que incluya la adopción de reformas institucionales que eviten que quienes buscan encontrar una ventaja personal en las compras públicas, tengan esa oportunidad (Chocano, 2020). Esta es una tarea pendiente y debe suponer la reorganización de la estrategia de contratación para despolitizar y eliminar la atomización de las decisiones de compra.

En esta ocasión, deseo sustentar algunas medidas que es preciso implementar para promover una mayor integridad en los mecanismos de contratación que las entidades han usado para procurarse bienes y servicios durante la emergencia ocasionada por la pandemia de la COVID-19.

Las entidades han contratado los bienes y servicios para la atención de las necesidades vinculadas a la pandemia a través de diversos procedimientos tales como la contratación directa por situación de emergencia, las contrataciones menores o iguales a ocho unidades impositivas tributarias, la comparación de precios, el catálogo electrónico de acuerdos marco, la contratación por encargo y la contratación internacional.

En ese sentido, a continuación, se analizará cada uno de esos mecanismos de contratación a fin de proponer algunas oportunidades de mejora que contribuyan a una gestión eficiente e íntegra de las contrataciones del Estado sobre todo en tiempos de emergencia como la que ha originado la propagación de la COVID-19.

Este trabajo propone la importancia de implementar un mecanismo electrónico que permita a las entidades realizar la contratación directa y las contrataciones menores o iguales a 8 UIT de una manera transparente y, en la medida de lo posible, competitiva. Estas contrataciones deben tener menos formalidades y plazos cortos. Sin embargo, la contratación debe ser transparente, lo que se podría lograr mediante una herramienta informática que las entidades deban usar para recibir las ofertas en este tipo de contrataciones y que estén disponibles al escrutinio público el mismo día en que se adjudica el contrato. Además, en la medida que las circunstancias lo permitan, las entidades deben poder realizar una convocatoria competitiva para recibir ofertas en estas contrataciones.

\section{Contratación directa por situación de emergencia}

El artículo 27 de la Ley $N^{\circ}$ 30225, Ley de Contrataciones del Estado (en adelante, Ley de Contrataciones) establece un número amplio de supuestos de contratación directa. El legislador ha considerado que son tres supuestos que habilitan a las entidades a contratar directamente, sin realizar un procedimiento competitivo y abierto a la participación de cualquier empresa.

Estos supuestos abarcan situaciones muy diversas, tales como la adquisición o arrendamiento de inmuebles; los servicios de publicidad en medios de comunicación; la contratación entre entidades públicas; los bienes y servicios que solo puedan obtenerse de un determinado proveedor; los servicios personalísimos; los servicios de consultoría 
que son una actualización de un trabajo previo realizado por un consultor individual; la adquisición de bienes y servicios con fines de investigación, experimentación o desarrollo de carácter científico o tecnológico; los servicios especializados de asesoría legal, contable, económica o afín para la defensa de funcionarios o ex funcionarios; los servicios de capacitación de interés institucional con entidades autorizadas u organismos internacionales especializados; la continuación de la ejecución de prestaciones no ejecutadas derivadas de un contrato resuelto o de un contrato declarado nulo; las contrataciones que con carácter secreto requieran realizar las Fuerzas Armadas, la Policía Nacional del Perú y los organismos conformantes del Sistema Nacional de Inteligencia; la contratación de emergencia y ante el desabastecimiento inminente.

La Ley de Contrataciones y su Reglamento, aprobado por Decreto Supremo N ${ }^{\circ}$ 344-3018-EF, establecen los requisitos que se deben verificar en cada uno de los supuestos para que la entidad esté habilitada a realizar la contratación directa.

En lo que va de 2020, la contratación directa es el procedimiento que más se ha utilizado y que ha adjudicado el mayor monto, muy por encima de las licitaciones públicas, concursos públicos y adjudicaciones simplificadas. Esta circunstancia es atípica y obedece al a emergencia sanitaria producto de la propagación de la COVID$19^{2}$.

La situación de emergencia es un supuesto de contratación directa reconocida en los compromisos que el Perú ha asumido a nivel internacional. Es razonable que, ante una situación de extrema urgencia, las entidades públicas estén habilitadas a contratar directamente, por invitación, sin realizar una convocatoria abierta a la participación de cualquier empresa.

Así, por ejemplo, el literal f) del numeral 1 del artículo 9.8 del capítulo 9 del Tratado de Libre Comercio con los Estados Unidos de América señala que una entidad puede contactar a un proveedor de su elección y no aplicar las reglas de una convocatoria abierta:

"cuando, por razones de extrema urgencia ocasionadas por acontecimientos imprevistos por la entidad contratante, no se pueda obtener las mercancías 0 servicios a tiempo mediante procedimientos consistentes con los Artículos 9.4 al 9.7 y el uso de esos procedimientos podría ocasionar un grave perjuicio para la entidad contratante" (Tratado de Libre Comercio con los Estados Unidos de América, 2006).

Asimismo, el numeral 5) del artículo 30 de la Ley Modelo de la Comisión de las Naciones Unidas para el Derecho Mercantil Internacional establece que una entidad puede contratar con un solo proveedor, entre otras circunstancias excepcionales, si debido a una situación de catástrofe, la necesidad del objeto del contrato es tan urgente que no resulta viable entablar algún otro método de contratación pública por el tiempo necesario para el empleo de esos métodos.

La normativa nacional regula la contratación directa por situación de emergencia en el literal b) del numeral 27.1 del artículo 27 de la Ley de Contrataciones del Estado y el literal b) del artículo 100 de su Reglamento.

La Ley describe cuatro supuestos de contratación directa por emergencia, los cuales son ampliados en el Reglamento, el cual además establece que esta causal de 
contratación directa está sujeta a regularización. Tres aspectos pueden mejorarse en la manera como se desarrolla la contratación directa por situación de emergencia:

\subsection{El criterio de contratar lo estrictamente necesario}

El penúltimo párrafo del literal b) del artículo 100 del Reglamento de la Ley de Contrataciones establece que cuando se verifica una situación de emergencia la entidad contrata de manera inmediata los bienes, servicios en general, consultorías u obras "estrictamente necesarios" para prevenir los efectos del evento próximo a producirse o atender los requerimientos generados por el evento producido.

Asimismo, el último párrafo de dicho literal subraya que la entidad únicamente está autorizada a contratar lo estrictamente necesario al señalar que, realizada la contratación directa, la entidad contrata lo demás que requiera para la realización de actividades de prevención y atención derivadas de la situación de emergencia y que no calificaron como estrictamente necesarias.

El criterio de contratar "lo estrictamente necesario" promueve, en la práctica, un enfoque legalista, y procedimental que no contribuye a la gestión por resultados y al mayor valor por dinero.

La entidad contratante debe diferenciar lo "estrictamente necesario" de aquello que no tiene ese carácter, para lo cual requerirá de la mayor cantidad de informes legales que le permitan sustentar tal criterio.

Todo ello con el riesgo de que el órgano de control, al evaluar si la entidad contrató más allá de lo estrictamente necesario, identifique algún tipo de responsabilidad en los funcionarios, aun cuando una evaluación basada en el valor por dinero y la gestión por resultados haya llevado al funcionario encargado de las contrataciones a tomar una decisión basada en el análisis costo beneficio antes que en un criterio legalista de lo estrictamente necesario.

Para ilustrar la dificultad de la aplicación práctica de este criterio pueden evaluarse las situaciones siguientes:

1. Debido a la emergencia sanitaria producto de la propagación de la COVID-19, una entidad requiere comprar mascarillas para sus funcionarios. ¿Cuál es la cantidad estrictamente necesaria para comprar?

2. El objetivo de la norma sería que se compre únicamente las mascarillas que se usarán mientras se realiza un procedimiento de selección competitivo. Entonces, ¿cuánto tiempo tomará ejecutar el procedimiento de selección? ¿Cuantifico un escenario ideal o realista? ¿Optimista o pesimista? Es decir, asumo que el procedimiento se puede declarar desierto o nulo, que puede ser objeto de una apelación, que el ganador no reunirá los documentos para firmar el contrato, etcétera; o, más bien, asumo que el procedimiento se va a ejecutar sin ningún inconveniente. La diferencia entre ambos escenarios son varios meses. ¿Qué criterio debe adoptar el funcionario para identificar la cantidad estrictamente necesaria?

3. Debido a las medidas de aislamiento para evitar la propagación de la COVID-19, el gobierno dispone que el banco estatal abra cuentas a nombre de un grupo de ciudadanos en estado de vulnerabilidad para depositar los bonos que viene implementando. Debido a la cantidad de nuevos beneficiarios, la implementación de tal medida requiere de la compra de un soporte informático que, ejecutándose de manera 
progresiva, puede demorar dieciocho meses. ¿Cuál es la cantidad de soportes informáticos estrictamente necesaria que la norma autoriza a comprar? ¿Podría comprarse todo el paquete incluso si la implementación culminase una vez ya superada la pandemia? ¿Qué sucede si resulta muy costoso comprar los soportes estrictamente necesarios para implementar de inmediato y dejar el resto a un procedimiento competitivo, lo que generaría la pérdida de un mejor precio por volumen? Nuevamente, ¿Qué escenario de duración del procedimiento de selección competitivo debe considerar el funcionario para contratar lo estrictamente necesario?

4. Un Hospital desea adquirir equipos médicos para atender a los pacientes que padecen los efectos de la COVID-19. Dichos equipos deben tener un mantenimiento preventivo cada seis meses, por el periodo de 3 años, a fin de conservar la garantía de fábrica del producto. ¿Podría contratarse de manera directa el equipo médico, incluyendo como prestación accesoria los seis mantenimientos preventivos? ¿Una prestación que se extiende durante tres años desnaturalizaría el carácter estrictamente necesario del contrato? ¿Sería razonable comprar únicamente el equipo y convocar un procedimiento de selección para el servicio de mantenimiento? ¿Sería acorde al principio de eficiencia si ello encarecería el costo de la contratación?

Como es de advertir, debido al temor que el órgano de control identifique un hallazgo y determine responsabilidades de índole administrativa, civil y penal en los funcionarios, las entidades públicas tenderían a ser conservadoras y preferir aplicar un criterio legalista aun cuando ello perjudique la eficiencia de la contratación.

Estas dificultades de aplicación práctica nos permiten sostener la conveniencia de eliminar el parámetro de contratar lo estrictamente necesario en la contratación directa por situación de emergencia y sustituirlo por el análisis costo beneficio, el valor por dinero y la gestión por resultados. De este modo, se busca dejar atrás el enfoque tradicional y legalista del proceso de compras, dando lugar a una visión moderna de la gestión de las contrataciones del Estado.

\subsection{La regularización de la contratación}

El literal b) del artículo 100 del Reglamento de la Ley de Contrataciones establece que la contratación directa por situación de emergencia se realiza de manera inmediata $y$, posteriormente, se regularizan los documentos de las actuaciones preparatorias, incluyendo el acto que aprueba la contratación directa, el contrato y sus requisitos.

Para la regularización, la entidad cuenta con un plazo de 10 días hábiles contados desde la fecha en que se entregó el bien o la primera entrega en el caso de suministros, o desde el inicio de la prestación del servicio o de la obra, según corresponda.

Debido a la necesidad de concentrar recursos en la atención de las necesidades derivadas de la emergencia sanitaria, diversos Decretos de Urgencia que han transferido recursos extraordinarios para realizar contrataciones vinculadas a la emergencia han ampliado el plazo para la regularización hasta 30 días hábiles, habiéndose otorgado plazos adicionales.

Corresponde preguntarse, sin embargo, si es posible encontrar mecanismos electrónicos a través de los cuales se ejecuten las contrataciones directas, que desaparezcan la necesidad de la regularización de la documentación. 
La regularización no es una buena práctica ni estándar internacional y además es irrazonable. ¿Por qué es necesario elaborar y firmar un contrato de un bien que ya se entregó y pagó? ¿Qué sentido tiene aprobar una compra de mascarillas que la entidad ya utilizó? ¿Para qué se necesita elaborar un informe que sustente una compra que ya se entregó a conformidad de la entidad?

La regularización de la documentación de una contratación ya ejecutada parecería buscar legitimar, a posteriori, la contratación realizada. Sin embargo, este es un mecanismo inconveniente y debe ser eliminado. En primer lugar, porque supone una desautorización del rol que ejerce el órgano encargado de las contrataciones en una entidad. Si el jefe de administración no tiene la autoridad de comprar un bien en una situación de emergencia, allí cuando más se necesita de su experiencia, ¿para qué existe su rol? ¿Por qué se tiene que involucrar a la más alta autoridad administrativa, que responde a intereses políticos, en un tema técnico y profesional como es la gestión de la logística de una entidad?

En segundo lugar, la regularización contribuye al excesivo formalismo de las compras públicas, que privilegia la elaboración de informes de sustento y la obtención de autorizaciones a la transparencia y libre competencia efectiva.

En tercer lugar, la regularización expone innecesariamente a un empresario a una situación injusta debido a que, luego de haber cumplido con entregar los bienes o prestar el servicio requerido, la entidad podría condicionar la autorización de la compra, lo que constituye también un alto riesgo de integridad. En los gobiernos regionales y locales, esta situación es aún más compleja debido a que la autorización de la compra depende de la decisión de los regidores que representan un interés político, no técnico.

Debido a los inconvenientes antes mencionados, es necesario implementar una herramienta informática a través de la cual los funcionarios difundan el requerimiento a contratar y reciban la propuesta de parte de los proveedores, de modo tal que se sustituya la necesidad de la regularización. Este mecanismo informático debe ser transparente y difundir la información de la contratación el mismo día en que se adjudicó el contrato. Y, en la medida de lo posible, la entidad debe realizar un procedimiento competitivo a través de esta herramienta informática. La emergencia debe significar una reducción de formalidades y plazos cortos, pero no menos transparencia y, en algunos casos, no menos competencia. Esta herramienta informática debe ser usada por todas las entidades públicas, tanto del gobierno nacional y local, las cuales utilizan diariamente el SEACE y otras herramientas electrónicas de contratación como los catálogos de acuerdo marco.

¿Por qué la ciudadanía debe esperar dos semanas, un mes, mes y medio o hasta dos meses para saber a quién se compró un bien a través de una contratación directa por emergencia? Un sistema de compras orientado a la prevención debe ser transparente. La notificación del proveedor seleccionado para ejecutar un contrato en una situación de emergencia debe realizarse a través de una plataforma informática de acceso público. De este modo, la ciudadanía podrá tener información oportuna sobre las contrataciones por situación de emergencia.

Esta implementación iría en línea asimismo con las recomendaciones formuladas por expertos que tuvieron a su cargo la gestión de adquisiciones en otras emergencias sanitarias. Así, por ejemplo, con base a la experiencia de compras en Sierra Leona durante la emergencia sanitaria por el brote del ébola, Smith consideró que la recepción de ofertas por email generó amplias oportunidades de corrupción y fraude. Por eso, estima que difundir convocatorias y recibir ofertas a través de una 
plataforma electrónica ofrece ventajas significativas en ahorro de tiempo, reduce los riesgos de corrupción e incrementa la seguridad y uso de datos (Smith, 2020).

De otro lado, cabe precisar que, según el Tribunal Constitucional del Perú, el principio de transparencia es fundamental en la contratación pública y comprende la publicidad de la convocatoria. En sentencia recaída en el expediente $\mathrm{N}^{\circ}$ 020-2003Al/TC, el Tribunal señala:

En términos generales, el principio de transparencia estará garantizado cuando haya publicidad en la convocatoria, en el adecuado control de calidad en los productos a adquirir, en los resultados de la evaluación de propuestas, y en el manejo de los recursos destinados a la compra en general.

En efecto, el artículo 76 de la Constitución Política del Perú prescribe que, por regla general, los procedimientos de contratación pública deben ser abiertos a la participación de cualquier empresa interesada.

Así, a la luz de la sentencia bajo comentario, el estándar constitucional exige que las entidades públicas promuevan la competencia en todo tipo de procedimiento de contratación pública, incluso en los supuestos de contratación directa, siempre que ello sea posible según las circunstancias de cada caso.

\subsection{La simplificación de la regulación}

El literal b) del numeral 27.1 del artículo 27 de la Ley de Contrataciones del Estado y el literal b) del artículo 100 de su Reglamento describen cuatro situaciones que configuran una situación de emergencia: (i) aquella derivada de acontecimientos catastróficos, (ii) las que afectan la defensa o seguridad nacional, (iii) las que supongan un grave peligro de que ocurra alguno de los dos supuestos anteriores; o, (iv) una emergencia sanitaria declarada por el ente rector del sistema nacional de salud.

De otro lado, la Ley de Contrataciones establece la posibilidad de contratar directamente ante una situación de desabastecimiento debidamente comprobada, que afecte $o$ impida a la entidad cumplir con sus actividades $u$ operaciones.

En tal sentido, el Reglamento señala que la situación de desabastecimiento se configura ante una ausencia inminente, debido a la ocurrencia de una situación extraordinaria e imprevisible, que compromete la continuidad de las funciones, servicios, actividades u operaciones que la entidad tiene a su cargo. Dicha situación faculta a la entidad a contratar solo por el tiempo o cantidad necesario para resolver la situación y llevar a cabo el procedimiento de selección que corresponda. Señala el Reglamento que no procede la contratación directa por desabastecimiento inminente en vías de regularización.

Ahora bien, a fin de simplificar la normativa de contratación pública, los cinco supuestos de contratación directa antes mencionados -cuatro situaciones de emergencia y una de desabastecimiento inminente- podrían fusionarse en un solo supuesto.

Una emergencia sanitaria como la pandemia de la COVID-19, un acto de terrorismo o una guerra pueden ser todos ellos considerados acontecimientos catastróficos. Del mismo modo, una catástrofe, tal y como ha sido definida por el Reglamento comparte con la situación de desabastecimiento inminente, su carácter extraordinario. Así pues, los cinco supuestos de contratación directa a las que se ha 
hecho referencia tienen, en realidad, una misma naturaleza, por lo que pueden ser objeto de una única regulación.

\section{Contrataciones menores o iguales a ocho (8) UIT}

La Ley de Contrataciones del Estado, que entró en vigencia el 9 de enero del 2016, modificó el ámbito de aplicación de la Ley precedente, incrementando de tres a ocho unidades impositivas tributarias el umbral para determinar la aplicación de la normativa de contratación pública.

Esta modificación buscó otorgar mayor flexibilidad a los procesos de contratación de las entidades, que contribuya a la eficiencia en la ejecución del gasto público. Tal y como menciona Azalea Chávez:

La posibilidad de que las entidades públicas puedan llevar a cabo contrataciones sin necesidad de iniciar la convocatoria de un procedimiento de selección, ha sido concebida con la finalidad de facilitar que las entidades del Sector Privado satisfagan de forma más rápida aquellas necesidades de reducido impacto económico (Chávez, 2017, p. 33).

En esta línea, el literal j) del artículo 64 del proyecto de Ley General de la Cadena de Abastecimiento, pre publicado por el Ministerio de Economía y Finanzas, ${ }^{3}$ establece que no se sujeta a licitación, concurso ni a las reglas de ejecución contractual, las contrataciones cuyos montos sean iguales o inferiores a 15 unidades impositivas tributarias, vigentes al momento de la transacción. De este modo, el sector busca dotar de mayor eficiencia y flexibilidad a la ejecución del gasto público.

Es importante dotar de mayor flexibilidad a las contrataciones del Estado. No obstante, a fin de evitar los riesgos a la integridad que hoy existen en las contrataciones menores, el aumento del umbral para la aplicación de la normativa de contratación pública debe realizarse una vez implementada una herramienta electrónica que permita a las entidades publicar sus necesidades y recibir ofertas de manera transparente en este tipo de contrataciones.

Las contrataciones menores a 8 unidades impositivas tributarias (en adelante, contrataciones menores) no se sujetan a la Ley de Contrataciones del Estado ni a su Reglamento, con excepción de algunas disposiciones puntuales.

Aplican los impedimentos para ser postor, participante, contratista o subcontratista establecidos en el artículo 11 de la Ley; la obligación de encontrarse inscrito en el Registro Nacional de Proveedores siempre que el monto involucrado sea superior a una unidad impositiva tributaria; la supervisión a cargo del Organismo Supervisor de las Contrataciones del Estado (OSCE), así como la obligación de registrar en el SEACE las contrataciones en un plazo de cinco días hábiles del mes siguiente de realizada la contratación, de acuerdo con lo dispuesto por la Directiva N 003-2020OSCE/CD.

A las contrataciones menores les aplica también la obligación de usar el catálogo electrónico de acuerdos, marco que administra la Central de Compras Públicas (PERÚ COMPRAS) siempre que la cuantía de la contratación sea superior al monto mínimo de atención establecido en el catálogo respectivo, que se sitúa alrededor de los quinientos soles. 
Además, el Tribunal de Contrataciones del Estado puede sancionar a las empresas que realicen contrataciones menores por la comisión de tres infracciones: (i) contratar estando impedidos según el artículo 11 de la Ley de Contrataciones; (ii) por presentar información inexacta o documentos falsos o adulterados en tales contrataciones; o, (iii) por suscribir contratos o acuerdos marco sin contar con inscripción vigente en el Registro Nacional de Proveedores.

EI OSCE ha publicado diversas opiniones vinculadas a las contrataciones menores en las que ha aclarado el alcance de la normativa de contratación pública a tal supuesto. Así, ha establecido que:

1. Estas contrataciones se rigen por las normas de organización interna de cada entidad, para lo cual, de acuerdo con lo establecido en los lineamientos internos, el órgano encargado de las contrataciones puede coordinar con el área usuaria para que brinde alcances sobre su necesidad, así como potenciales proveedores y costos estimados (Opinión Nº 042-2020/DTN).

En esta opinión, la Oficina General de Administración del Ministerio de Economía y Finanzas había consultado si los lineamientos internos de una entidad podían establecer que las áreas usuarias debían brindar al órgano encargado de las contrataciones información sobre el profesional o técnico a contratar, así como el costo estimado de la contratación.

Esta interrogante es clave a fin de delimitar las responsabilidades por la elección y costo de las contrataciones menores. Existen directivas y lineamientos internos aprobados por diversas entidades que invierten las responsabilidades en las contrataciones menores, estableciendo que es responsabilidad del área usuaria remitir al órgano encargado de las contrataciones el monto y consultor elegido, pese a que, según los roles propios de cada función, tales responsabilidades corresponderían más bien al área que tiene a su cargo el abastecimiento de la entidad.

2. La entidad puede establecer que las empresas deban presentar los documentos que se estimen convenientes en cada caso (Opinión $N^{\circ}$ 007-2020/DTN).

En esta opinión, el Subgerente de Logística y Servicios Generales de la Municipalidad Distrital de Ventanilla consultó si podía exigirse a los proveedores que presenten con carácter obligatorio una declaración jurada para que declare que no tiene impedimento para contratar con el Estado, según el artículo 11 de la Ley de Contrataciones del Estado.

La exigencia de la declaración antes referida es, sin duda, muy importante toda vez que dicho artículo establece que los impedimentos para contratar se aplican también a las contrataciones menores, por lo que las entidades deben garantizar que los proveedores declaren tal condición antes de contratar. De este modo, la opinión bajo comentario destaca que las entidades tienen libertad de establecer los documentos que deba presentar la empresa en las contrataciones menores.

3. Las fichas técnicas del listado de bienes y servicios comunes aprobadas por la Central de Compras Públicas - PERÚ COMPRAS para el uso de la subasta inversa electrónica son obligatorios también para las contrataciones menores o iguales a 8 unidades impositivas tributarias (Opinión N²076-2019/DTN).

Esta consulta fue realizada por la empresa Emcure Pharma Perú S.A.C. a fin de confirmar que la normativa ha establecido que las características técnicas 
estandarizadas en una ficha técnica aprobada por Perú Compras deben usarse para las contrataciones menores aun cuando éstas no se encuentren dentro del ámbito de aplicación de la Ley de Contrataciones del Estado.

4. En las contrataciones menores o iguales a 8 unidades impositivas tributarias, cuando el requerimiento haga referencia a fabricación, marca, patentes 0 tipos, la entidad puede, de considerarlo necesario, disponer que se cuente con un informe que sustente la referencia a una marca o tipo particular para garantizar la funcionalidad, operatividad o valor económico del equipamiento o infraestructura preexistente de la entidad (Opinión Nº97-2016/DTN).

En este caso, el Superintendente Adjunto de Administración General de la Superintendencia de Banca, Seguros y Administradoras Privadas de Fondos de Pensiones consultó si se debía realizar un proceso de estandarización cuando el requerimiento hace referencia a una marca.

Esta opinión aclara que los requerimientos por las contrataciones menores puedan hacer referencia a marcas, siendo recomendable que exista un informe de sustento similar al que se exige en la normativa de contratación pública en el procedimiento de estandarización regulado por la Directiva № 006-2016-OSCE/CD.

5. Los profesionales y técnicos del órgano encargado de las contrataciones de la entidad que se dedican exclusivamente a gestionar contrataciones menores 0 iguales a 8 unidades impositivas tributarias requieren contar con certificación emitida por OSCE. (Opinión Nº 097-2016/DTN).

Así, OSCE ha interpretado que, en tanto las contrataciones menores son contrataciones públicas, aplica también la obligación de los profesionales y técnicos que intervienen en alguna fase de la contratación de encontrarse certificado ante OSCE.

6. La entidad que requiera efectuar contrataciones menores debe observar los principios que rigen la contratación pública, así como garantizar la eficiencia y transparencia en el uso de los recursos públicos (Opinión N²00-2017/DTN). De este modo, se aclara que las entidades deben promover los principios establecidos en la Ley de Contrataciones, aun cuando esta no resulte aplicable, debido a la finalidad pública que se busca conseguir a través del abastecimiento público.

7. Las entidades deben verificar que a través de las contrataciones menores no se está eludiendo la aplicación de la normativa de contratación pública, ni se ha transgredido la prohibición de fraccionamiento (Opinión No 167-2017/DTN). De este modo, se refuerza la obligatoriedad establecida en la Ley de Contrataciones de no dividir artificialmente una contratación a fin de evadir la realización de un procedimiento de selección abierto o competitivo.

8. Si se realiza una contratación menor con alguien que está impedido para contratar con el Estado, la entidad tiene la facultad de declarar la nulidad del contrato (Opinión $N^{\circ}$ 075-2017/DTN). De este modo, la opinión bajo comentario garantiza el cumplimiento de los impedimentos establecidos en el artículo 11 de la Ley de Contrataciones a las contrataciones menores.

Ahora bien, los medios de comunicación han llamado la atención sobre la integridad con la que se ejecutan las contrataciones menores debido a la contratación del señor Ricardo Cisneros por parte del Ministerio de Cultura. Este caso ha puesto en evidencia que, a entender de los órganos de control, las contrataciones menores 
deberían cumplir de manera estricta las disposiciones y lineamientos internos que aprueban las entidades para gestionar las contrataciones menores.

La situación expuesta por los medios de comunicación evidencia que los funcionarios públicos necesitan de mecanismos transparentes y competitivos para ejecutar las contrataciones menores en las que no se aplica la Ley de Contrataciones del Estado. La implementación de una plataforma informática, como la propuesta para la gestión de las contrataciones directas, contribuiría a una mayor transparencia y competencia en las contrataciones menores.

Pero, además, en el caso específico de los servicios profesionales de carácter técnico y especializado, es necesario contar con un régimen normativo específico que pondere de manera equilibrada por un lado, la necesidad que los funcionarios cuenten con cierto margen de apreciación personal al evaluar el currículum, la experiencia y trayectoria de un consultor que no se base únicamente en parámetros objetivos reglados $y$, por otro lado, la importancia de promover una competencia justa entre distintos consultores. Este es un desafío que corresponde abordar para fortalecer la eficiencia e integridad en las contrataciones menores.

De otro lado, debe eliminarse la práctica de las entidades de contratar personal subordinado a través de las contrataciones menores. De acuerdo con un informe de la Autoridad Nacional del Servicio Civil (SERVIR), la informalidad en el sector público ascendería a $11 \%$. Estos trabajadores del sector público serían contratados mediante órdenes de servicio a través de las contrataciones menores. Es decir, se trata de profesionales y técnicos que realizan actividades subordinadas, pese a que son contratados mediante órdenes de servicio aparentemente para prestar servicios autónomos. Esta práctica debe eliminarse. Para hacer viable esta eliminación, es necesario que las entidades identifiquen la real dimensión de su necesidad de personal y las condiciones de los servicios requeridos para determinar el tipo de contrato aplicable.

Uno de los problemas que el OSCE ha alertado recurrentemente es el incumplimiento de las entidades públicas de la obligación de registrar las órdenes de compra y servicio menores a ocho unidades impositivas tributarias en el SEACE. Así, por ejemplo, mediante nota de prensa del 10 de septiembre de 2020, advirtió que más de 1,400 entidades públicas no habrían cumplido con dicha obligación ${ }^{4}$. Esta situación es un grave problema de transparencia en este tipo de contrataciones menores y podría ser superado con la implementación de la plataforma informática antes comentada.

Es importante precisar que los contratos menores se distinguen de la contratación directa. Estos mecanismos de contratación suelen confundirse porque a las contrataciones menores se les suele denominar, en la práctica, "compras directas".

No obstante, cabe precisar que a las contrataciones menores no les aplica la Ley de Contrataciones del Estado, ni su Reglamento salvo disposiciones específicas establecidas expresamente en tal normativa, así como algunas otras que han sido objeto de interpretación por el OSCE mediante opiniones.

En cambio, la contratación directa es un procedimiento de selección establecido en dicha normativa. No obstante, tal normativa ha exceptuado la aplicación de las reglas de la fase de selección, manteniendo la aplicación de las disposiciones referidas a las fases de actuaciones preparatorias y ejecución contractual de la normativa de contratación pública. 


\section{Comparación de precios}

La comparación de precios es un procedimiento de selección de competencia restringida. No es abierto a la participación de cualquier empresa, sino que únicamente participarán aquellas que el funcionario público elige a discreción. El órgano encargado de las contrataciones debe comparar las ofertas de por lo menos tres proveedores y elegir como ganador al que ofertó el menor precio.

La comparación de precios no se puede usar para cualquier objeto contractual. Únicamente se ha autorizado para la contratación de bienes y servicios en general. Es decir, no se puede contratar una consultoría ni ejecutar una obra a través de este procedimiento. Además, los bienes y servicios deben reunir las siguientes características:

1. Disponibilidad inmediata. Es decir, que se entreguen o implementen dentro de los 5 días siguientes de formalizada la contratación.

2. Que cumplan con las especificaciones técnicas o términos de referencia sin necesidad de ser fabricados, producidos, modificados, suministrados o prestados siguiendo la descripción particular de la entidad.

3. Que sean fáciles de obtener o que tengan un estándar establecido en el mercado.

La comparación de precios se ha utilizado para contratar diversos bienes y servicios vinculados a la emergencia sanitaria, tales como el servicio de aplicación de pruebas rápidas, la adquisición de mascarillas de diverso tipo, mandiles, pantalones y chaquetas descartables, la adquisición de pruebas rápidas de descarte, alcohol en gel, termómetros infrarrojos, protectores faciales, frazadas antialérgicas, bolsas para el traslado de cadáveres, entre otros equipos de protección de personal y dispositivos hospitalarios.

El monto máximo autorizado para realizar una comparación de precios es de 15 unidades impositivas tributarias (S/ 64,500.00 en el 2020).

\section{Catálogos electrónicos de acuerdo marco}

La Central de Compras Públicas - PERÚ COMPRAS ha convocado diversos procedimientos de selección para suscribir acuerdos marco con proveedores que puedan atender requerimientos vinculados con la emergencia sanitaria.

Así, se ha puesto a disposición de las entidades un catálogo electrónico para la adquisición de material de protección para la salud de uso no hospitalario, que incluye guantes de látex, mascarillas para uso ocupacional y alcohol en gel; así como un catálogo para la adquisición de pruebas serológicas rápidas para descarte de la COVID19.

Es importante que las entidades tengan una herramienta que les permita comprar bienes de manera segura y a un precio competitivo. En la primera convocatoria del procedimiento para material para la salud de uso no hospitalario, Perú Compras evaluó los contratos de distribución y cartas de representación de las empresas participantes, lo que les permita tener certeza de la condición de distribuidor autorizado de los productos ofertados en el catálogo. 
Es importante que se implementen más catálogos electrónicos de acuerdos marco, ya que ello contribuye a la eficiencia del proceso de contratación, al evitar que las empresas presenten documentación a cada entidad que requiera de sus servicios. Asimismo, los catálogos permiten a los funcionarios públicos contar con un mecanismo ágil para identificar la oferta de determinado producto, así como la tranquilidad que la evaluación de los requisitos documentales de la empresa ya haya sido realizada de manera centralizada por Perú Compras.

\section{Contratación por encargo}

Las entidades públicas pueden encargar la realización de las actuaciones preparatorias y el procedimiento de selección a otra entidad pública o a un organismo internacional, conforme al artículo 6 de la Ley de Contrataciones.

El encargo a una entidad pública requiere de un informe técnico legal que sustente la necesidad y viabilidad del encargo. No se establecen parámetros específicos para la realización de ese informe, por lo que queda a criterio de la entidad establecer los motivos que la llevan a encargar las actuaciones preparatorias o el procedimiento de selección a otra entidad pública. Tales razones podrían obedecer a la capacidad operativa de la entidad, así como la especialidad y complejidad de la contratación, por ejemplo. El informe de sustento es aprobado por el titular de la entidad, según lo señalado en el artículo 109 del Reglamento de la Ley de Contrataciones.

El encargo de un procedimiento de selección a una entidad pública constituye un encargo de gestión, definido como "la posibilidad que la realización de actividades con carácter material, técnico o de servicios de competencia de un órgano sea encargado a otros órganos o entidades" (Guzmán, 2015, p. 147).

Además del informe técnico legal, se requiere la suscripción de un convenio interinstitucional que determine las condiciones del encargo, incluyendo, entre otros, la competencia para la aprobación del expediente de contratación y de los documentos del procedimiento de selección.

Durante la emergencia sanitaria, mediante Decreto de Urgencia $N^{\circ} 028-2020$ "Dictan medidas extraordinarias en materia económica y financiera para la adquisición de pruebas de diagnóstico para la prevención y control del COVID-19"-, se autorizó a la Central de Compras Públicas - PERÚ COMPRAS, a efectuar las contrataciones de bienes y servicios para la obtención, transporte y procesamiento de muestras para el diagnóstico de la COVID-19, de manera excepcional, durante el año 2020, a requerimiento y a favor del Instituto Nacional de Salud. Tratándose de un régimen especial establecido por ley, esta autorización excepcional no se sujeta a las disposiciones señaladas del Reglamento de la Ley de Contrataciones del Estado para la realización de los encargos a entidad pública.

El requerimiento inicial a Perú Compras supuso una transferencia de alrededor de cien millones de soles, a los que se adicionó otros ciento veinticuatro millones para continuar atendiendo las necesidades del Instituto Nacional de Salud, para comprar pruebas rápidas, pruebas moleculares, insumos y equipos de laboratorio para el diagnóstico molecular.

Es de destacar el portal de transparencia que Perú Compras ha implementado para difundir la información vinculada a los contratos realizados producto de este encargo. Cualquier ciudadano puede identificar de manera sencilla los requerimientos 
contratados, en ejecución, así como las empresas invitadas, las que enviaron cotización y las que fueron adjudicadas en cada uno de esos requerimientos.

Asimismo, se puede identificar rápidamente el listado de empresas adjudicadas y las órdenes de compra emitidas, lo que contribuye a la transparencia y al uso de información por parte de los ciudadanos. De acuerdo con la información que obra en el portal, al 6 de diciembre de 2020, se ha contratado alrededor de 195 millones de soles, siendo la empresa Deltalab Perú la que tiene el mayor monto adjudicado con alrededor de 72 millones 5 .

Las contrataciones por encargo deben impulsarse sobre todo como una herramienta de consolidación de la demanda de varias entidades. La centralización de este tipo de contrataciones contribuiría a la eficiencia de los procesos de contratación toda vez que se evitaría la duplicidad de la inversión de recursos administrativos destinados a la procura de bienes y servicios. Esta centralización es prioritaria a nivel local debido a la atomización existente en las decisiones de compra de las municipalidades.

De otro lado, el encargo a un organismo internacional tiene pautas específicas para su procedencia. Debe tratarse de un organismo internacional acreditado y referirse a objetos contractuales que, dada la envergadura, complejidad o insuficiente capacidad técnica de la entidad, requieran de un apoyo técnico de mayor especialización. Además, esta justificación debe constar en el expediente. Es decir, la entidad debe sustentar que no es capaz de comprar determinado bien, contratar un servicio o ejecutar una obra.

La aprobación del encargo a un organismo internacional es formal e indelegable. En el caso de los poderes ejecutivo, legislativo, judicial y tratándose de los organismos constitucionales autónomos, se aprueba por el titular de la entidad; en el caso de los Gobiernos Regionales y Locales, por acuerdo de Consejo Regional o Concejo Municipal, según corresponda; y para las empresas del Estado, por Acuerdo de Directorio.

Adicionalmente, el encargo debe constar en un convenio específico para cada procedimiento de selección, detallando las obligaciones y responsabilidades de cada una de las partes, entre otros requisitos establecidos en el Reglamento.

Durante la emergencia sanitaria, mediante Decreto de Urgencia № $110-2020$ que dicta medidas extraordinarias para facilitar y garantizar la adquisición, conservación y distribución de vacunas contra la COVID-19 publicado en el Diario Oficial El Peruano el 10 de septiembre de 2020, se autorizó al Ministerio de Salud a efectuar las adquisiciones de vacunas contra la COVID-19 a través de organismos internacionales u otras formas de asociación u organización, para lo cual se suscriben los convenios de cooperación técnica que resulten necesarios.

Así, se ha excluido de la aplicación de la Ley de Contrataciones todos los actos necesarios para la adquisición, conservación, distribución y aplicación de dichas vacunas, no siendo aplicables las disposiciones comentadas del Reglamento para estas contrataciones.

\section{Contratación internacional}

De acuerdo con el literal f) del artículo 5 de la Ley de Contrataciones, no resulta de aplicación dicha Ley a las contrataciones realizadas con proveedores no domiciliados en el país cuando se sustente la imposibilidad de realizar la contratación a través de los 
métodos de contratación de la norma, o cuando el mayor valor de las prestaciones se realice en territorio extranjero.

Dos supuestos permiten a una entidad no usar los métodos de contratación previstos en la normativa nacional para contratar con una empresa no domiciliada en el país. De un lado, la imposibilidad de realizar la contratación mediante la normativa, por ejemplo, debido a que no existe oferta en el mercado nacional y el proveedor no domiciliado que puede brindar el servicio no contrata en el ámbito de la normativa nacional. Este supuesto se verifica por ejemplo en la compra de algunos productos farmacéuticos innovadores. De otro lado, cuando el mayor valor de las prestaciones se realiza fuera del país, por ejemplo, cuando se contratan servicios de catering y alimentación en el marco de una convención de negocios en el exterior en las que el Perú participa con un stand.

Debido a que no es de aplicación la normativa nacional, el proveedor no domiciliado no requiere estar inscrito en el Registro Nacional de Proveedores. Este supuesto de inaplicación otorga flexibilidad a la entidad para contratar con un proveedor que no tiene interés en registrarse en dicho registro ni prestar servicios en el país.

Ahora bien, la Décimo Octava Disposición Complementaria Final de la Ley de Contrataciones, amplió los supuestos de contratación con no domiciliados cuando el ente rector del Sistema Nacional de Salud, esto es, el Ministerio de Salud, sustente que dicha contratación resulta más ventajosa. Esta disposición también resulta de aplicación para el Seguro Social de Salud (ESSALUD), para la adquisición de productos farmacéuticos o dispositivos médicos.

De este modo, en el ámbito del sector salud, las entidades en cuestión pueden realizar un análisis costo beneficio y determinar si les resulta más ventajoso realizar la contratación con un proveedor no domiciliado, sin sujetarse a la aplicación de la normativa de contratación pública nacional, aun cuando no se verifiquen los supuestos establecidos en el literal f) del artículo 5 de la Ley.

Así, por ejemplo, el Centro Nacional de Abastecimiento de Recursos Estratégicos en Salud - CENARES ha realizado indagaciones de mercado para justificar la compra directa a un no domiciliado de 166,200 tabletas de linezolid de $600 \mathrm{mg}$ justificando un ahorro de alrededor de tres millones de soles, según el informe técnico publicado en el SEACE.

Este método de contratación se ha utilizado para realizar contrataciones vinculadas a la atención de las necesidades surgidas por la propagación de la COVID19 , tal y como, por ejemplo, para la adquisición de productos farmacéuticos para el tratamiento del coronavirus.

En comparación con la contratación directa por situación de emergencia, la contratación internacional de un no domiciliado no requiere dilucidar el carácter "estrictamente necesario" del requerimiento, evitándose incurrir en los problemas a los que se ha hecho referencia en el acápite de la contratación directa por emergencia.

\section{Conclusiones}

Es importante evaluar la forma en que se han gestionado las contrataciones para la atención de las necesidades surgidas durante la emergencia sanitaria producto de la propagación de la COVID-19. La estrategia de contratación ha evidenciado los retos pendientes para hacer más eficiente la contratación pública, a través de la mejora de la 
coordinación entre las entidades y el impulso a la centralización de la contratación pública.

La falta de integridad es un problema de larga data que los medios de comunicación y órganos de control han puesto de manifiesto incluso durante la catástrofe sanitaria en momentos en los que corresponde todavía más exigir un alto grado de vocación de servicio e integridad en los funcionarios públicos.

En este artículo hemos revisado los distintos mecanismos que han usado las entidades públicas para proveerse de los bienes y servicios necesarios para atender la emergencia sanitaria, y quisiera destacar las siguientes tres propuestas de mejora:

1. Es prioritario implementar una herramienta electrónica que permita a las entidades publicar sus necesidades y recibir ofertas de manera transparente en las contrataciones directas por situación de emergencia, así como en las contrataciones menores o iguales a ocho unidades impositivas tributarias.

La urgencia en la atención de las necesidades y la escasa cuantía de las contrataciones menores justifican establecer plazos cortos y reducir formalidades. No obstante, no debe significar una demora en la transparencia de la información. Resulta necesario implementar una herramienta informática que difunda toda la información de dichas contrataciones tan pronto como se adjudica el contrato. La forma de notificación al contratista de la buena pro debe ser esa herramienta informática.

Las entidades deben promover que las contrataciones directas y las contrataciones menores sean abiertas a la participación de cualquier empresa, salvo que ello no sea posible según las circunstancias concretas.

La implementación de esta herramienta informática podría reducir la necesidad de usar un procedimiento como la comparación de precios, que no es abierto a la libre competencia.

2. El criterio legalista de comprar lo "estrictamente necesario" a través de una contratación directa por situación de emergencia debe eliminarse y dar paso a una evaluación de la contratación a través de los principios de mayor valor por dinero, gestión por resultados y análisis costo beneficio. Asimismo, una vez implementada la herramienta informática propuesta, debe eliminarse la obligación de "regularización" de este tipo de contratación directa.

3. Es necesario adoptar un régimen normativo específico para la contratación de servicios profesionales por montos menores a las 8 unidades impositivas tributarias que pondere de manera equilibrada la necesidad que los funcionarios cuenten con cierto margen de apreciación personal al evaluar el currículum, la experiencia y trayectoria de un consultor; así como la promoción de una competencia justa entre distintos consultores. Las contrataciones menores no deben usarse para la contratación de trabajadores informales.

4. Las contrataciones por encargo deben impulsarse sobre todo como una herramienta de consolidación de la demanda de varias entidades. La centralización de este tipo de contrataciones contribuiría a la eficiencia de los procesos de contratación toda vez que se evitaría la duplicidad de la inversión de recursos administrativos destinados a la procura de bienes y servicios. Esta centralización es prioritaria a nivel local debido a la atomización existente en las decisiones de compra de las municipalidades. Del mismo modo, es importante que se implementen más catálogos 
electrónicos de acuerdos marco, ya que ello contribuye a la eficiencia del proceso de contratación.

\footnotetext{
1 Información disponible en el siguiente portal de la Contraloría General de la República: https://emergenciasanitaria.contraloria.gob.pe/ces_funcionarios-servidores/index.html (Consultado el 10 de octubre de 2020).

${ }^{2}$ Según información actualizada al 18 de agosto de 2020, en el Perú, el monto adjudicado en los tres años previos mediante contratación directa ha sido de S/ 2447.8 millones en 2017; S/ 2 648.3 millones en 2018 y S/ 2816.3 millones en 2019. Información disponible en el portal Conosce, sección estadísticas generales de contrataciones públicas (https://portal.osce.gob.pe/osce/conosce/indicadores-del-mercado-estatal.html).

${ }^{3}$ La publicación del proyecto de Ley, así como de su exposición de motivos y ayuda memoria pueden ser consultados en el siguiente enlace: https://www.mef.gob.pe/es/pre-publicacion-deley (Consultado el 4 de octubre de 2020).

4 Dicha nota de prensa puede ser consultada en el siguiente enlace: https://www.gob.pe/institucion/osce/noticias/302039-osce-mas-de-1-400-entidades-publicas-nohabrian-cumplido-con-la-obligacion-de-registrar-ordenes-de-compra-y-de-servicio-en-el-seace (Consultado el 04 de octubre de 2020).

5 Información disponible en el portal de transparencia COVID-19 de PERÚ COMPRAS: https://www.perucompras.gob.pe/contrataciones/contrataciones-emergencia-COVID19.php (Consultado el 6 de diciembre de 2020).
}

\section{Referencias}

Brown, F.; Brechenmacher, S. y Carothers, T. (6 de abril de 2020). How Will the Coronavirus Reshape Democracy and Governance Globally? Carnegie Endowment for International Peace. https://carnegieendowment.org/2020/04/06/how-will-coronavirus-reshapedemocracy-and-governance-globally-pub-81470

Chávez, A. E. (2017). El fraccionamiento indebido en la contratación de servicios públicos de telecomunicaciones por montos menores a las 8 UITs [Tesis de Maestría, Pontificia Universidad Católica del Perú]. http://tesis.pucp.edu.pe/repositorio/handle/20.500.12404/1306

Chocano, C. (2020) Herramientas para la integridad en la contratación pública peruana / Tools for integrity in peruvian public procurement. Revista de Derecho Administrativo $N^{\circ}$ 18. Círculo de Derecho Administrativo, 35-65. http://revistas.pucp.edu.pe/index.php/derechoadministrativo/article/view/22856

Gallego, J. A..; Prem, M. \& Vargas, J. F. (5 de julio de 2020). Corruption in the Times of Pandemia. https://papers.ssrn.com/sol3/papers.cfm?abstract_id=3600572

Guzmán, C. (2015). Proceso de Selección por Encargo. Derecho \& Sociedad, (44), 145153. http://revistas.pucp.edu.pe/index.php/derechoysociedad/article/view/14396

Kaufmann, D. y Kraay, A. (2018). Indicadores de gobernanza mundial. https://info.worldbank.org/governance/wgi/

OCDE (2017). Recomendación del Consejo de la OCDE sobre Integridad Pública. http://www.oecd.org/gov/integridad/recomendacion-integridad-publica

Smith, C. (28 de abril de 2020) What I learned from tackling Ebola: we need to prioritize agile, electronic procurement systems to beat COVID-19. https://www.opencontracting.org/es/2020/04/28/what-i-learned-from-tackling-ebola-we-need-toprioritize-agile-electronic-procurement-systems-to-beat-COVID-19/

Transparencia Internacional (2019). Índice de percepción de la corrupción. https://www.transparency.org/cpi2019 